\title{
BOEKBESPREKING: LIEFDE EN LENTEBLOESEMS, CHINESE EROTISCHE SCHILDERKUNST
}

Erotische kunst in China is oud cultuurgoed. Al in de oudheid, in elk geval vanaf de Han-dynastie (206 v.Chr.-220 n.Chr), was er al sprake van erotische afbeeldingen. Het begrip 'lentebloesems' refereert aan een traditie uit de oudheid waarbij jongens en meisjes elkaar toezongen tijdens het lentefestival om elkaar te verleiden. Het bekijken van naakte personages in opzienbarende houdingen was in het pre-moderne China in kringen van de elite geen stuitende bezigheid. Dergelijke afbeeldingen hingen niet als een kunstwerk aan de muur, maar lagen opgeborgen en werden slechts in intieme vriendenkring bekeken. Soms bestudeerden twee geliefden tezamen albumbladen of een boek met erotische afbeeldingen, ter lering maar ook ter vermaak.

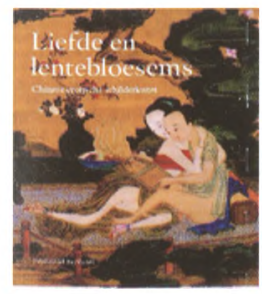

\section{Achtergronden van de Chinese erotische kunst}

Ruim een jaar geleden kwam het prachtige boek Liefde en lentebloesems van Ferdinand Bertholet uit. Niet alleen de ruim 100 erotische prenten die in kleur zijn afgebeeld vormen een schoonheid om naar te kijken. Ook de teksten van Bertholet en Pimpaneau maken het geheel een genot om te bestuderen.

Ferdinand Bertholet verzamelt al ruim twintig jaar Chinese erotische schilderkunst. In zijn korte inleiding vertelt de verzamelaar, kunstschilder en restaurator Bertholet over de geschiedenis van zijn collectie. Het begon ooit met de uitgave Chinese Erotic Art van Michel Beurdeley die Bertholet recht in het hart trof vanwege de decoratieve kracht en de heldere kleurencombinaties van de afgebeelde prenten uit de Kangxi-periode (1662-1722). Deze waren een bron van inspiratie voor zijn eigen kunstschilderwerk. Jaren later tijdens zijn eerste reis door Azië vormde de aankoop van een serie grote albumbladen met erotische schilderingen in Hong Kong het begin van zijn inmiddels indrukwekkende verzameling. De erotische prenten geven niet alleen een erotische gebeurtenis weer, zij vertellen ook veel over de gangbare mode, kleding en haardracht, interieuren en binnentuinen die behoorden bij een bepaalde sociale status, in een bepaalde periode van de Chinese geschiedenis.

Jacques Pimpaneau, emeritus hoogleraar, heeft een boeiend essay geschreven over erotiek in het oude China. Hij benadrukt dat de band tussen zonde en erotiek in China niet bestond. 'Erotiek wordt slechts als verkeerd gezien in de mate waarin ze eigenschappen doet verloochenen die wezenlijk zijn in een samenleving, zoals trouw, het gestand doen van een gegeven woord en toewijding aan ouders en vaderland.' Hij vervolgt: 'Uit de literatuur blijkt dat het Chinese denken maar moeilijk kan begrijpen wat man en vrouw zou moeten weerhouden van datgene waaraan beiden genoegen ontlenen, tenzij het tot leugenachtigheid leidt.' (p. 16) Ook homoseksualiteit owas zeer 23 09:21:00AM aanwezig in de erotische kunst. Men zag dat niet als zondig. Pimparieaur lichicess 


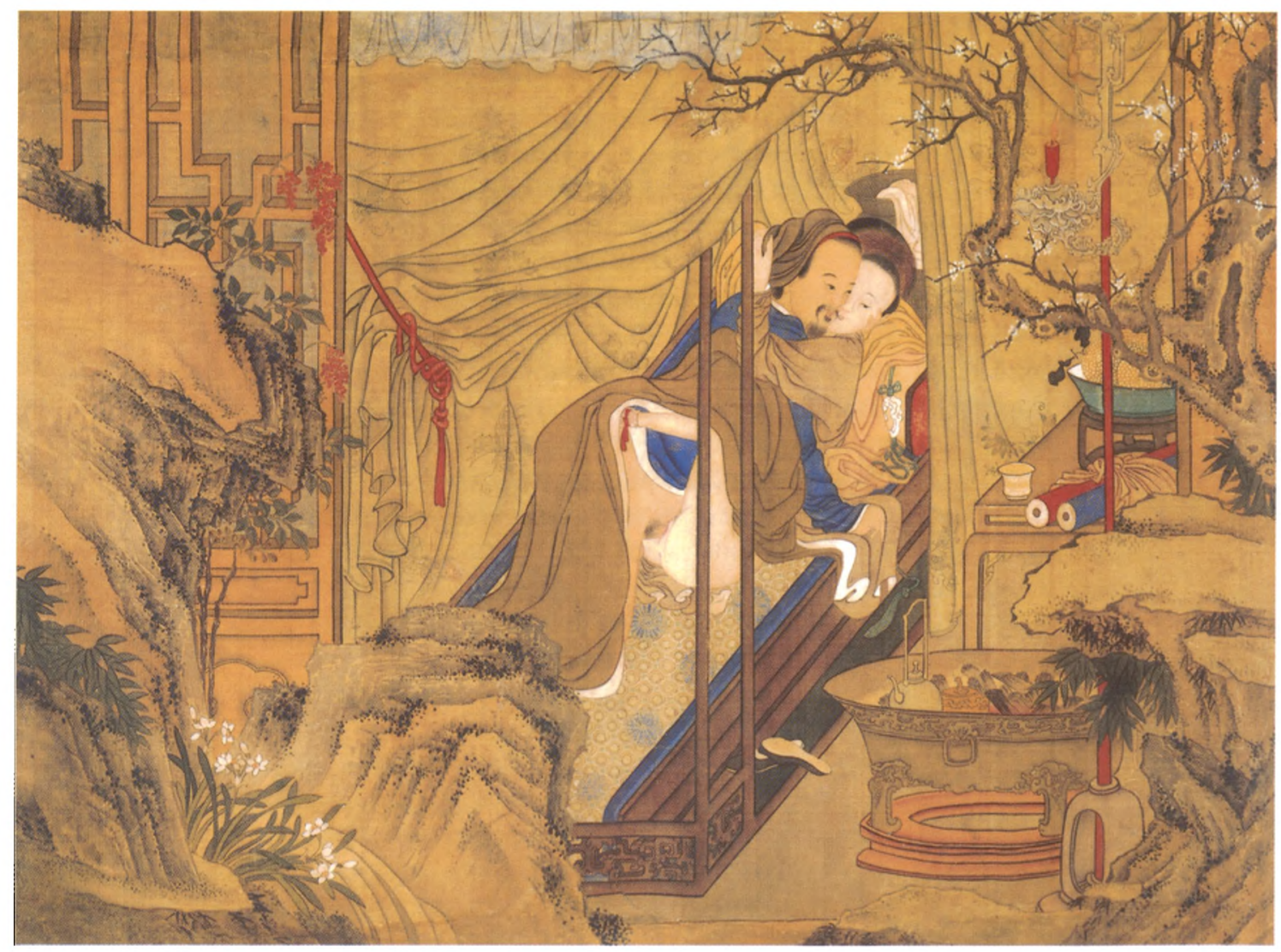

Afbeelding 1 Warme wijn in een koude nacht, inkt en kleuren op zijde, ca. 1700 , Liefde en lentebloesems, p. 87 toe dat dit alles niet betekent dat Chinezen vroeger seksueel vrijzinnig waren. Het confucianisme voorzag in beperkende voorschriften en een strak familiaal keurslijf. Pimpaneaus tekst is interessant om te lezen, vooral vanwege het feit dat hij steeds literaire en historische bronnen aanhaalt.

Beide schrijvers laten zien welke invloed religieuze ontwikkelingen hebben gehad op het beschrijven en het afbeelden van seksuele handelingen. Het boeddhisme zag geen kwaad in seksuele vereniging, wel in ontrouw, begeerte of wreedheid. Maar vooral de invloed van het daoïsme op de erotiek was groot. Seks had niet in de eerste plaats voortplanting of lustbevrediging tot doel, maar het behoud en de verlenging van het leven.

\section{De praktijk van de Chinese erotische kunst}

In de Chinese erotische kunst wordt seks nooit pornografisch geschetst. Vrouwen lijken altijd vrijwillig en vol plezier deel te nemen aan de seksuele betrekkingen. En mannen tonen nergens een overdreven wellust.

De bloeiperiode van de Chinese erotische kunst was aan het einde van Mingperiode (1368-1644). Toen de dynastie in verval raakte, bloeide de Chinese erotische kunst en steeg de kwaliteit vande erotische prenten aanzienlijk $0: 21: 00 \mathrm{Am}$ De uitgesproken erotische literatuur van die bloeitijd leverde een aantaf ${ }^{\text {ree }}$ access 


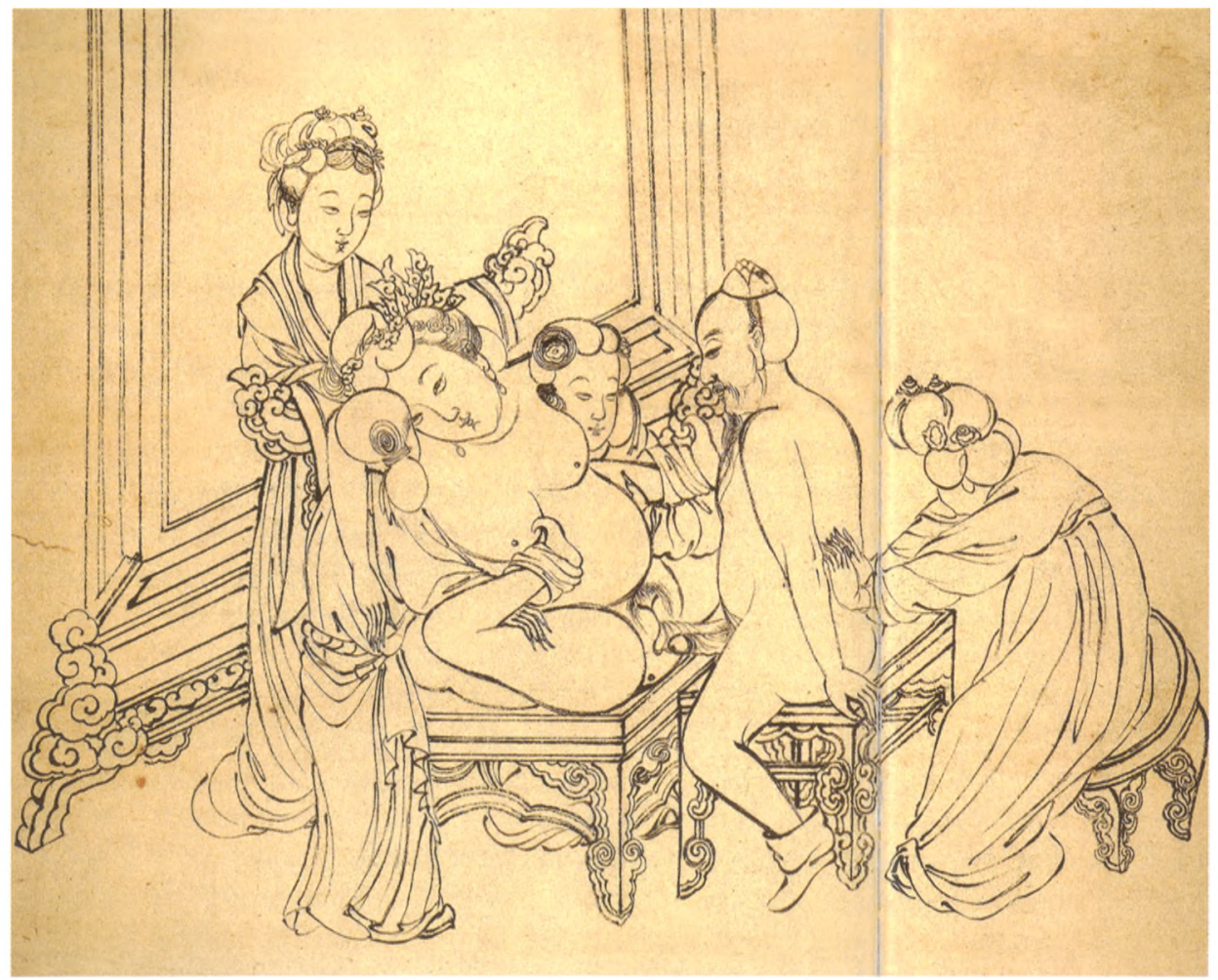

Afbeelding 2 Keizer Xuanzong en zijn concubine Yang Guifei, inkt op papier, $19^{\circ}$ eeuw, Liefde en lentebloesems, p. 161 klassiekers op, zoals Jin Ping Mei ('pruimenbloesem in gouden vaas'), Rou putuan ('de bidmat van vlees') en Hong Lou Meng ('droom in de rode kamer'). De boeken werden verluchtigd met erotische schilderingen.

De oorspronkelijke prenten zijn helaas verdwenen.

De eerste afbeeldingen in het boek Liefde en lentebloesems zijn oude erotische schilderingen op zijde, uit de late Ming. Ze komen uit een gesigneerd album van Wang Sheng, een hoge ambtenaar die het zelf schilderde met een eenharige penseel. De prenten worden vergezeld van gedichten in diverse kalligrafiestijlen. De meeste schilderingen in het boek zijn $18^{\mathrm{e}}$-eeuws, van onbekende meesters. Veelal zijn de schilderingen op zijde, soms op papier. Bertholet voorzag elk hoofdstuk van informatie over technieken en materiaal. Tegelijk vestigt hij de aandacht van de kijker op de details, de schoonheid van een compositie en de daoïstische invloeden, zoals die zijn terug te zien in het lijnenspel.

Opvallend in de afbeeldingen is het veel voorkomende voyeurisme. Soms gluurt een man door een raam, kijkend naar een naakte badende vrouw. Vaak is er sprake van een extra deelnemer, een dienares of een oude vrouw, die het vrijende stel een helpende hand biedt. Soms ook zien we afbeeldingen met meerdere minnenden, zoals de student en de drie jonge meisjes in de serie de bidmat van vlees. Niet zelden is de kijker zelf aan het'igluren' door 21: ๑๑ AM bijvoorbeeld een opengeschoven gordijn of een poort. 
De personages verschillen van de naakten in de Westerse beeldtraditie.

De omtreklijnen van de lichamen worden niet in detail weergegeven, ze lijken wel opblaasbaar. Vaak zijn de vrouwenborsten bedekt. Als ze zichtbaar zijn, zijn ze klein. Het lichaam van een man is meestal onbehaard en wat mollig. Zowel mannen als vrouwen worden niet seksueel overdreven afgebeeld. Hun figuren volgen niet de Westerse conventies van ronde, rondborstige vrouwen en gespierde, behaarde mannen.

\section{Tot slot}

Het bekijken van de schilderingen krijgt een andere dimensie als de Westerse kijker zich ervan bewust is dat er geen moralistische boodschap verborgen zit in de erotische afbeeldingen. Erotiek was niet zondig tenzij het gezin en staat in gevaar bracht, zoals de liefdesrelatie tussen de Tang-keizer Xuan Zong (712-756, posthume naam Ming Huang) en de beroemde concubine Yang Guifei, die een goed bestuur van de staatszaken in de weg stond. In het oude China was het afbeelden en beschrijven van seks geen platte, wellustige bezigheid, omdat seks bovenal werd beschouwd als de sleutel naar het eeuwige leven en als goed voor de gezondheid van man en vrouw.

- Ferdinand M. Bertholet, Liefde en lentebloesems; Chinese erotische schilderkunst Oorspronkelijke titel: Les Jardins du Plaisir: Erotisme et Art dans La Chine ancienne Editions Phillippe Rey, Parijs, 2003

Gebonden,192 pagina's met meer dan 100 afbeeldingen in kleur ISBN 90-77204-12-1 